\title{
Large serrated polyps: molecular and familial links to a serrated neoplasia predisposition
}

\author{
Matthew F Kalady ${ }^{1,2^{*}}$, Kathryn DeJulius ${ }^{1}$, Anna Bennett ${ }^{3}$, James M Church ${ }^{1,2}$ \\ From 13th Annual Meeting of the Collaborative Group of the Americas on Inherited Colorectal Cancer \\ Honolulu, Hawaii, USA. 16-17 October 2009
}

\section{Background}

The serrated pathway to colorectal cancer is associated with a CpG-island methylator-phenotype (CIMP) and is distinct of the classical adenoma-to-carcinoma sequence. There is increasing evidence that a subset of hyperplastic polyps (HPs) serves as intermediates in an oncogenic sequence resulting in a CIMP colorectal cancer. This study analyzes molecular changes in large HPs to define their potential relationship to the serrated polyp pathway and links them to a predisposition to colorectal cancer.

\section{Methods}

Large serrated polyps $(>20 \mathrm{~mm}$ ) were identified by review of a colorectal polyp database and corresponding paraffin-embedded pathology specimens were retrieved. DNA was isolated from tissue blocks and methylation-specific quantitative real-time PCR analysis (MethyLight) was used to determine CIMP status (5 marker panel), methylation of mutated in colon cancer (MCC) gene, and the MLH1 gene. Polyp DNA was screened for mutations in the oncogenes KRAS and BRAF. Patient personal and family history of colorectal cancer was reviewed.

\section{Results}

Thirty-four large serrated polyps were studied. 28 were analyzed for BRAF of which 26 (93\%) were mutant at V600E. 30 polyps were analyzed for CIMP, of which 18 (60\%) were CIMP+. Of the 28 BRAF mutants, 20 had CIMP analysis done as well: 12/20 (60\%) were CIMP+ and $8 / 20(40 \%)$ were CIMP-. Of the $12 \mathrm{CIMP}+$, BRAF mutant polyps, 3 of 4 had methylated MCC but none of 4 had methylated MLH1. All polyps were KRAS wild type. 22 patients with large serrated polyps had an available personal and family history. Eight of 22 (36\%) had

\footnotetext{
* Correspondence: kaladym@ccf.org

'Department of Colorectal Surgery, Cleveland Clinic, Cleveland, Ohio 44195, USA
}

a personal and 6 of $22(27 \%)$ had a family history of colorectal cancer. Six of the eight (75\%) with a personal history and 3 of the $6(50 \%)$ with family history of colorectal cancer were CIMP+.

\section{Conclusions}

Large serrated polyps represent a subset of serrated lesions that appear to be initiated by BRAF mutations and progress toward cancer through subsequent methylation events. These polyps are associated with significant personal and familial history of colorectal neoplasia and likely represent part of a serrated neoplasia disposition.

\section{Author details}

'Department of Colorectal Surgery, Cleveland Clinic, Cleveland, Ohio 44195, USA. ${ }^{2}$ The Sanford R. Weiss Center for Hereditary Colorectal Neoplasia, Cleveland, OH, USA. ${ }^{3}$ Department of Anatomic Pathology, Cleveland Clinic, Cleveland, Ohio 44195, USA.

Published: 25 May 2010

doi:10.1186/1897-4287-8-S1-P7

Cite this article as: Kalady et al:: Large serrated polyps: molecular and familial links to a serrated neoplasia predisposition. Hereditary Cancer in Clinical Practice 2010 8(Suppl 1):P7.

Submit your next manuscript to BioMed Central and take full advantage of:

- Convenient online submission

- Thorough peer review

- No space constraints or color figure charges

- Immediate publication on acceptance

- Inclusion in PubMed, CAS, Scopus and Google Scholar

- Research which is freely available for redistribution

Submit your manuscript at www.biomedcentral.com/submit
C Biomed Central 